\author{
SCENTIA INTERNATIONAL ECONOMIC REVIEW \\ Volume 1 - Issue 1 - 2021
}

\title{
Robust maritime supply chains -
}

\author{
What contribution can optimization potentials for container terminals \\ make to the entire supply chain?
}

\begin{abstract}
Benjamin Bendel, Comenius University, Bratislava, Slovakia Jochen Schwenk, Comenius University, Bratislava, Slovakia

Milan Fekete, Comenius University, Bratislava, Slovakia
\end{abstract}

\begin{abstract}
Container terminals are an important interface in the maritime supply chain, as they connect the geographically localized last mile to the customer and the shipping company. Its handling efficiency makes a decisive contribution to the fact that the maritime supply chain functions in a high-performance way. The aim of this article is to identify and describe potential optimization potentials in operational operation for container terminals. The focus is on the interfaces to the most important stakeholders of the container terminal, i.e., water-side handling, yard, and intermodal transport. For this purpose, the method of qualitative content analysis as outlined by Mayring was used. The software MaxQDA was used to code the given literature and analyze its content. In the given literature 12 categories were identified and 786 codes and subcodes were analyzed. The basic barriers to optimization of container terminals have been identified by this study.
\end{abstract}

Keywords: Maritime Supply Chain, Container Terminals, Optimization Potentials, Maritime Stakeholders, Wasser-Side Envelope, Railway Terminal, Land-side envelope

JEL Codes: R40, R41 


\section{Introduction}

The global supply chain is the logistical backbone to deliver the globalized flows of goods, which are produced cost-effectively at decently distributed locations, in the right quantity, the right capacity, at the right price and at the right time to the right consumer.

The business models of e-commerce providers such as Amazon from the USA and Alibaba from China are based on the five essentials of logistics mentioned above. But car manufacturers such as Daimler and BMW or chemical producers such as BASF also rely on efficient supply chains for sales, procurement and finishing of the products at several production stages and at several locations. These supply chains must not only function efficiently, but also demonstrate so-called resilience. Resilience ${ }^{1}$ is a "swinging" state into which the supply chain can be returned in a timely manner if there are exogenous disturbances. A recent example of exogenous disorder is the COVID-19-pandemic, which has temporarily isolated manufacturers and consumers from different countries geographically and requires a re-design of the supply chain.

The maritime supply chain in container transport considered here basically consists of the stakeholders shipping companies, ports, and container terminals as well as the hinterland transporters ${ }^{2}$ and the customers and consignors. Whenever the low-cost sea transport for goods is preferred by the consignor and consumer over the higher transport tariffs for express goods in air transport and long-term planning of shipping and reception is possible, containerized sea transport is the preferred choice of logistics service providers.

Container terminals are an important interface in the maritime supply chain, as they connect the geographically localized last mile to the customer and the shipping company. Its handling efficiency makes a decisive contribution to the fact that the maritime supply chain as a whole function in a high-performance way.

\section{Methods used}

This study is intended to carry out a qualitative content analysis. Rather, it is about creating understanding in causalities. The defined institutions serve as a research object here. ${ }^{3}$ In this case, literature serves as data material. This type of data is suitable as a unit of analysis of qualitative ${ }^{4}$ research. This literature is analyzed as part of a coding

\footnotetext{
${ }^{1}$ The term resilience for the property of supply chains is closely related to the term "robust". Tang (2006) defined on p. 33f a robust supply chain as follows: "a robust supply chain should enable a firm to manage regular fluctuations in demand efficiently under normal circumstances regardless of the occurrence of a major disruption".

The resilience of a supply chain is lt. Collins English Dictionary "the ability of a system to return to its original (or desired) state after being disturbed".

${ }^{2}$ Hinterland transporters are logistics service providers that transport containers to the recipients by truck, train or inland waterway.

${ }^{3}$ Hussy et al., 2010

${ }^{4}$ Mayring, 2015
} 
process 5 . MaxQDA has been used in this regard. In the given literature 12 categories were identified and 786 codes and subcodes were analyzed.

\subsection{0bjective}

The aim of this article is to identify and describe potential optimization potentials in operational operation for container terminals. The focus is on the interfaces to the most important stakeholders of the container terminal, i.e. on the water-side envelope, yard, and intermodal transport.

\subsection{Research Question}

Based on the current relevance of the study object, the following research question can be deduced: What are potential optimization potentials in operational operation for container terminals?

\section{Introduction to how a container terminal works}

A sea container terminal - inland container terminals in the port hinterland are no longer considered here - has the purpose of efficiently implementing the handling of sea containers to the end customer.

A minimum time handling time (residence time at the container terminal until collection by the logistics service provider) is considered "efficient", considering a profit-making for the handling by the operator of the container terminal. Theoretically, maximum handling efficiency is achieved when the container is loaded directly from unloading the container ship on the container yard onto one of the means of transport by rail, truck or inland waterway. However, this theoretical situation will only be feasible in individual cases since the timetables of railways and inland waterway vessels as well as the pick-up time of the logistics service provider by truck must be considered.

To ensure an economically viable utilization of the means of transport, container volumes are initially bundled on the container terminal. See figure 1 for details. 


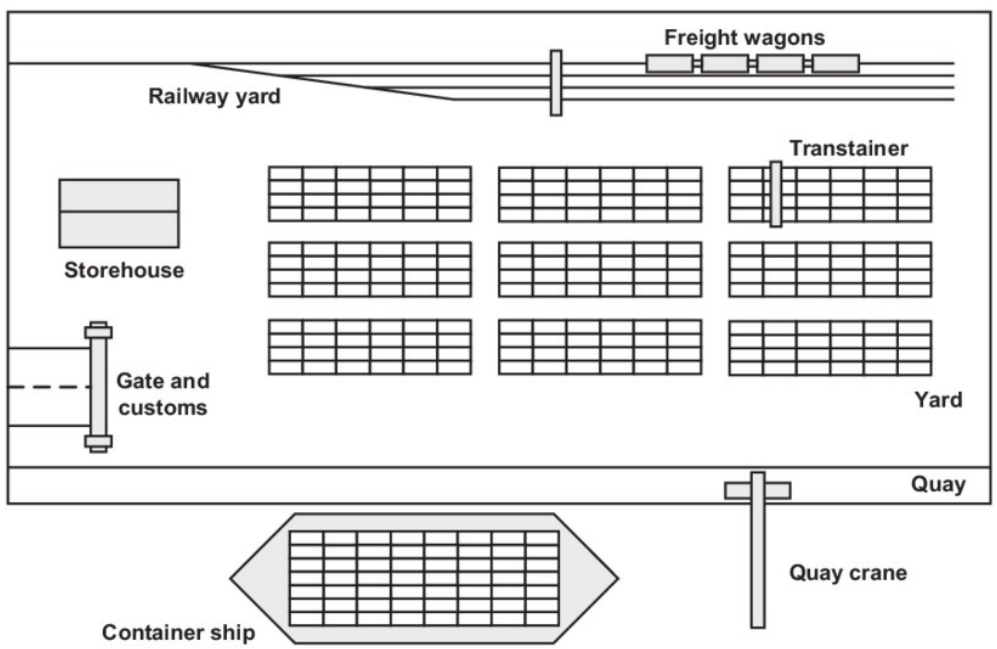

Fig1. Schematic layout of a sea container terminal

Source: Modeling and optimal receding-horizon control of maritime container terminals (2007)

Starting from the water side with the berths, the containers are unloaded/loaded by quay cranes and stacked in blocks on the yard, depending on the onward transport. Landside cranes (transtainers) manage the sorting of the containers in the blocks on the yard. In this case, the transport of the containers on land takes place exclusively by freight wagons on a railway terminal (railway yard).

The delivery/removal of the containers is carried out by truck through a gate, where customs (Customs) and administrative data of the accompanying documents are checked

First, the main challenges for the container terminal operator must be identified because they provide the basis for the optimization potentials to be discussed later.

The operator of a container terminal faces four fundamental challenges:

- High investment costs for the construction of the container terminal (infrastructure) combined with immobile assets at the respective geographical location,

- container volumes are volatile depending on $10{ }^{6}{ }^{6}$ volumes, the shipping companies in progress and the ship sizes used,

- there are capacity problems of the container terminal due to very high container volumes when loading/deleting large container ships ("Peak Load Problem"),

- there is a dependence on the local port infrastructure, such as gutters depth and other nautical conditions.

The investments for container terminal operators focus on hardware in terms of terminal vehicles, container bridges and on-land terminal cranes, as well as on software, for example for the Terminal Operating System (TOS) and various systems for the control of terminal equipment and financial administration.

\footnotetext{
${ }^{6}$ Loco may stand for Local Content. This refers to the geographically relevant catchment area for the contain terminal, for example in regions such as the Hanseatic city of Hamburg.
} 
Due to their immobile location, container terminals can only control the geographical centre of gravity as an attraction for container handling to a limited extent. From the land side, the volume of containers is controlled by the shippers, who offer their logistic services depending on the demand of the end customers. The local volume of goods in the geographically relevant catchment area (Loco volume) for containerized cargo is an essential basis for the shipping companies to call at the container terminal and determines the start-up frequency and the ship sizes used.

If one looks at the so-called water side with the berths, the shipping companies determine the volume of containers by the planned ship calls as well as the ship sizes used. The productivity of the container terminal, the services offered and the handling prices, in addition to the loco volume of the departure density of container ships, determine the attractiveness as a regional transshipment point for consignors.

The time of unloading and loading of the container ship leads to the so-called peak load problem, because a container ship wants to minimize its residence time at the berth in the port. During this time, the container terminal operator must use a corresponding capacity of terminal equipment, which is not required continuously in time, as there is no continuous occupancy of the berths at the container terminal. In the off-peak load times, the infrastructure and terminal hardware are not fully utilized and incur opportunity costs in the form of empty costs. Depending on the conditions of competition, the container terminal operator may pass on the marginal costs for handling the container volumes to the shipping companies through additional handling charges ${ }^{7} 8$ during the "On Peak Time". 9

The dependence of container terminal operators on the local port infrastructure is evident. Where appropriate ship sizes call at the port, necessary water depths and conservation measures for the depth of the water are required, which are subsumed under the term "nautical conditions". Decisions on and responsibility for the nautical conditions do not lie directly with the container terminal operator but with the port authority. If the required water depth is not maintained, certain ship sizes can only call at the port partially unloaded, which is not very attractive from the point of view of the shipping companies.

Investments ${ }^{10}$ in container terminals are long-term over periods of 20 to 40 years and require high volumes. In contrast, volatile markets represent freight rates and changes in global economic dynamics. There is therefore an investment risk, as many capital goods such as container ships or terminal equipment find only a few customers and are generally classified as non-liquid assets. In addition, it should be borne in mind that the investments described tie up significant financial resources (working capital), which, for example, has a direct impact on the free cash flow available for dividend distributions to shareholders.

\footnotetext{
${ }^{7}$ On the theory of marginal costs, see Beck p. 94-95

${ }^{8}$ A detailed discussion of the application of marginal costs in the pricing of transport infrastructure can be found at Hensher and Brewer (2001), p. 172-184

${ }^{9}$ Shipping companies and terminal operators charge so-called Congestion Surcharges for handling charges under specially defined circumstances.

${ }^{10}$ See on the financial mathematical methods and economic framework conditions Keipinger and Burga (2016)
} 
As a result, optimization can basically be achieved through process optimization, which in turn is a consequence of investments in hardware and software. In addition to the desired process optimization, technical and economic aspects must be considered in the short, medium, and long term.

\subsection{Stakeholders}

Optimization potentials in container terminals must always be considered from the point of view of cooperation between various stakeholders and weigh edits in their effects. For example, extensive exchange of documents such as the B/L and information on container status (location, loading status, customs) between the shipping company, the container terminal and the logistics service providers is required. In this process, there are different processing speeds of the information as well as different IT systems and interfaces.

If all participants work profit-maximizing, cooperation can involve both equilateral and mutual interests in container transport.

The term maritime container shipping refers to all container transports with oceancompatible container ships. This means that maritime container shipping (Deepsea) is properly separated from short sea shipping near the coast and transport by inland waterway.

Ship sizes with a load capacity of up to 24,000 TEU are used today. The term TEU (Twenty Foot Equivalent) refers to the standard measure of 20' for a container. Container ships with 25,000 TEU are discussed in the design. It is not foreseeable at this stage whether these ship sizes will be used and should not be considered at this point. 111213

In the further course of this section, the main stakeholders will be briefly described:

The port, represented by the Port Authority, provides the infrastructure (e.g., port access, berths, electricity connection) and, in the case of so-called PPP (Private Public Partnership) models, also the terminal infrastructure (terminal area, earthworks, access, etc.). In the use of the infrastructure, shipping companies and container terminal operators must pay user charges, such as concession fees, to the Port Authority. The superstructure (terminal equipment, software) is procured and operated by the users under their own corporate responsibility.

The shipping company operates a fleet of container ships and charges a transport tariff for container transport at the consignor. Some shipping companies have financial holdings or their own subsidiary in container terminals. One example is the Danish logistics group A.P. Moeller-Maersk with its subsidiary APMT.

The container terminal operator takes over the container handling at the container terminal for a fee. The handling includes the loading/unloading of the container ship, the storage of the container on the terminal, customs clearance, and other services. Container terminal operators and shipping companies conclude contracts for handling charges and planned container handling volumes.

\footnotetext{
${ }^{11}$ The HMM Algeciras of the shipping company Hyundai Merchant Marine is with a load-bearing capacity of 23.964 TEAs, which is currently container ship in the world (stand: January 2021) Source: https://schiffsradar.org/hmm-algeciras/

${ }^{12}$ A design design by the shipping company COSCO with a load capacity of 25,000 TEU is being discussed. Source: Maritime gateway from 28.03. 2019
} 
The logistics service provider in the port carries out service services such as sea-based storage and packaging of the sea container (stuffing \& stripping) as well as the land-side container transport to/from the shipper/end customer. Depending on the contract, various means of transport, such as trucks, railways, or inland waterways, are integrated into the supply chain. A distinction is made between the Merchant Haulage and Carrier's Haulage types for the contract models.

At Merchant Haulage, individual services in container logistics are carried out by various independent contractors, such as container transport to/from the port, while at Merchant Haulage a contractual partner (shipping company or logistics service provider) offers all services from shipping the container to arriving at the recipient from a single source. The part of shipping at Carrier's Haulage lies in the uniform overall organization and liability for the contractual provision of services.

\section{Results - Optimization potentials}

In section 1.2, a first reference to possible optimization potentials has already been made regarding the challenges for the container terminal operator. If the focus for optimization is on the integration of the container terminal into global supply chains, the processes on the water side, the yard and in the rail terminal for inland transport are to be considered in connection. Only if these three sub-processes work synchronously can a holistic optimization be realized. In this section, the above-mentioned sub-processes will be analyzed and discussed based on exemplary contributions with selected optimization potentials. The following Fig. 2 shows an exemplary selection of exogenous and endogenous disturbances that inhibit the handling process of a container on the terminal at its handling speed. 


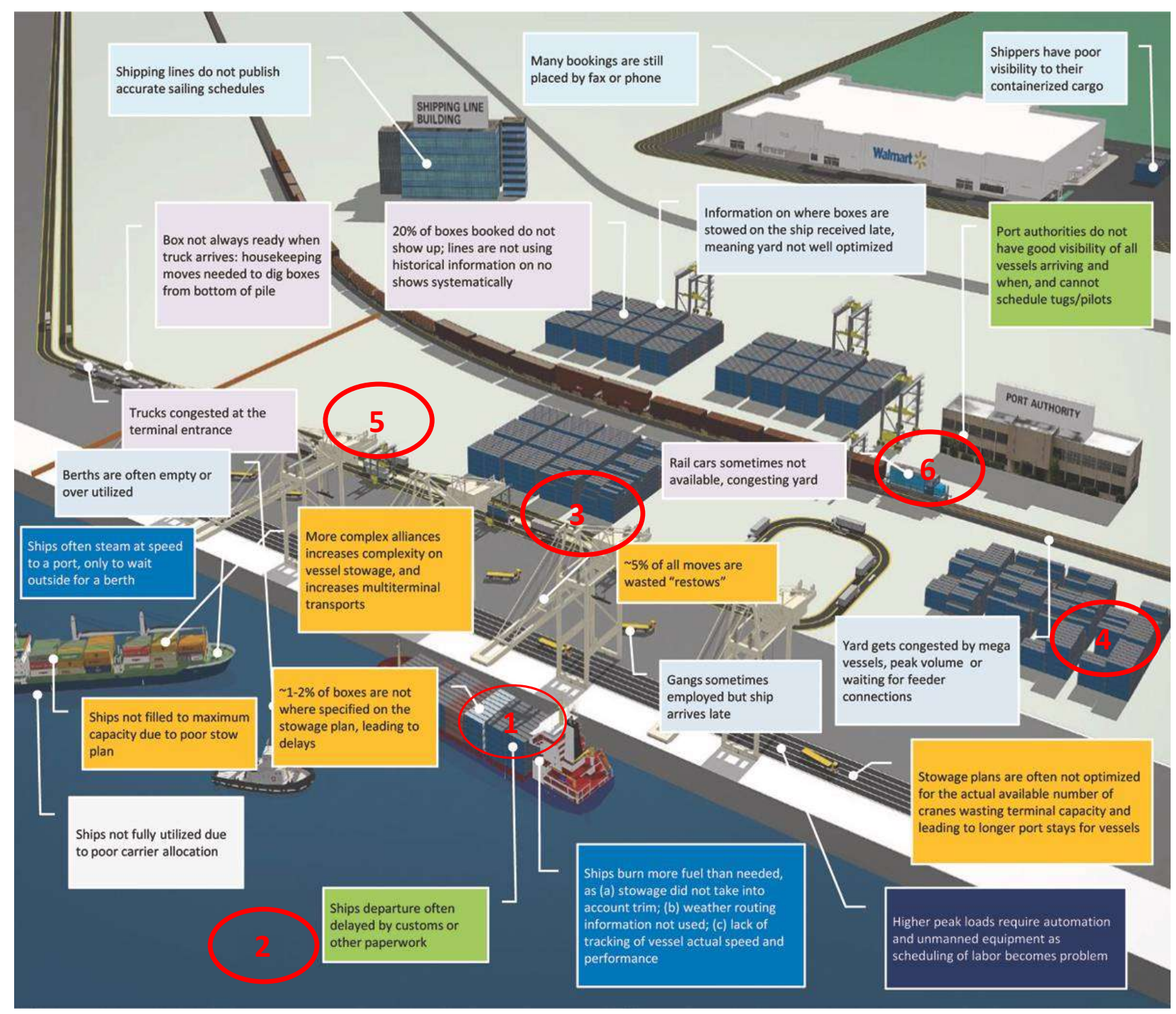

Fig. 2 Exogenous and endogenous sources of interference on sea container terminals

Source: https://www.maritimeprofessional.com/news/navis-puts-cloud-305999

Exogenous faults are sources of interference that the container terminal operator cannot influence. This includes, for example, an unplanned ship start-up.

Endogenous faults are sources of interference resulting from the container terminal operator's internal operations. This includes, for example, an unsynchronized planning of container stacking on the yard.

In the further discussion, the red-rimmed disturbance variables 1 to 6 from Figure 2 are discussed separately for the identified three sub-processes water side, yard and railway terminal and solution sketches are presented.

\subsection{Waterfront}

The subject of consideration is the berths and the unloading/unloading of the ships by STS (Ship-to-Shore Crane) for stacking the containers on the yard. 
Figure 2 exemplifies two problem areas and outlines a solution.

Problem 1: up to $-2 \%$ of all containers are not in the place as they appear in the ship's congestion plan. This causes time delays in loading/deleting the ship.

Problem 2: The departure of the ship is delayed by an unclear customs status or missing documents.

Problems 1 and 2 are mainly due to an unsynchronized provision of information between the shipping company, container terminal, ship and customs. For example, containers that arrive at the terminal and are still scheduled by the shipping company on the ship are responsible for such delays. The reason for this is that each container must be cleared and planned separately in the congestion planning of the terminal and the ship. However, the corresponding IT systems are not synchronously networked in time, so that cumbersome rescheduling can occur due to resource reallocation during container transport on the terminal and loading onto the ship.

The US software manufacturer NAVIS is the world's leading provider of Terminal Operating Software (TOS) for container terminals and proposes the use of a cloud-based collaboration platform NAVIS XVELA for solving the above-described problem 1 and 2 . The TOS is a central element in the control of container flows from the water side of the container terminal via the landside

Yard to the transport of the containers on the land side by truck, train, or inland waterway. With the help of the TOS, the container terminal operator plans, controls and monitors all processes with the core functions of ship congestion planning, device control, billing modalities, resource planning and customs processes.

Fig. 3. demonstrates the four sub-functions of the collision platform NAVIS XVELA: congestion planning (Stowage Planning), real-time shared information, cooperation functions (cooperation tools) and joint exchange of performance data of the process (Shared Performance Analysis

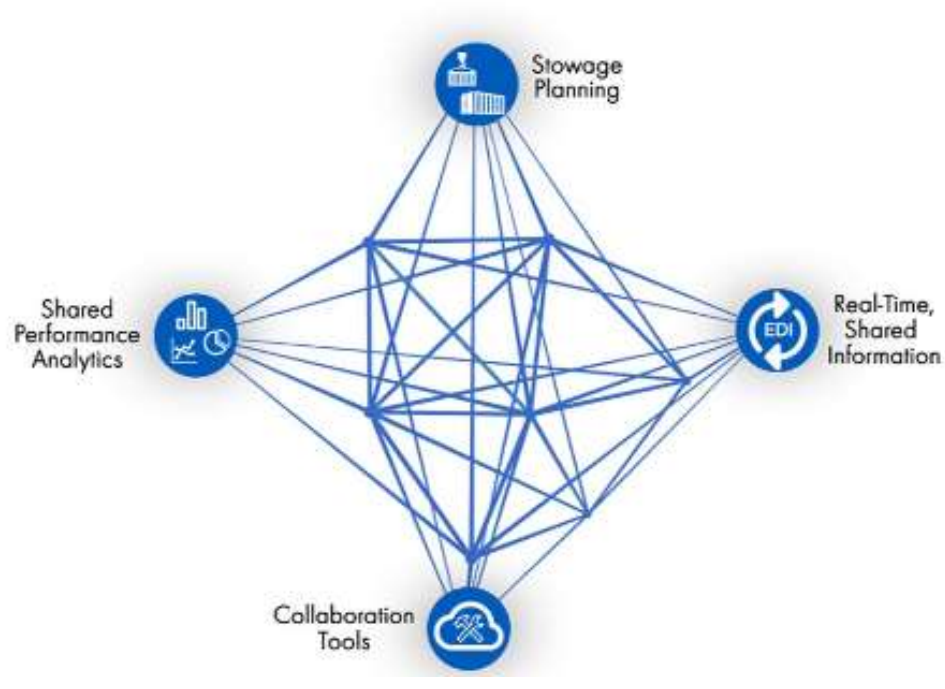

Fig. 3 Collision platform NAVIS XVELA 
The shipping company plans to load a ship by container on a route with fixed port calls on a route based on container bookings targeted by customers. The aim of the shipping company is to fully utilize the container parking spaces and to minimize the short dwell times at the Terminal, and to minimize the cost of the ship via the itinerary. The task of the shipping company is to plan the container unloadings/loads along the itinerary in such a way that the over-stacking of container during port calls on the ship is minimized. Any stacking of containers on the ship requires time, because it occupies crane capacity on the water side of the container terminal. This process is called optimal ship congestion planning.

The container terminal operator aims to make optimum use of the maximum handling capacity with a given area by minimizing the container's residence time on the terminal. The planning process aims to position containers on the terminal in a timely manner before loading/unloading the ship on the terminal in a mirror image to the ship's congestion plan to minimize container transport movements. The result is an optimal congestion plan from the planning of the container terminal operator. ${ }^{14}$

With this approach, the terminal operator maximizes its revenues at the given costs of terminal operation and the investment costs incurred.

Each container occupies scarce footprints. Various restrictions prevent the container storage capacity on the terminal surface from exceeding certain stack heights. These restrictions

include but are not only the load capacity of the floor, the technical performance of terminal equipment, working time regulations and natural influences such as wind.

In addition, it should be noted that changes in the planning bases, for example due to delayed ships or unplanned container deliveries on the land side, result in an increasing number of re-stacking processes of containers on the terminal. These restacks take time and take up equipment resources. ${ }^{15}$

In the transfer zone $\mathbf{1 6}$ of the terminal, the containers for the inland transport by truck, train, or inland waterway to/from the recipient/consignor of the container are handed over/received. The logistics service providers in hinterland transport determine their departure times/arrival times according to individual timetables or in the case of truck transports after the route optimization of the freight forwarders.

The container terminal operator can only exert limited influence on these individual processes, for example by means of "cut-off time windows",i.e.. determine the time of the latest delivery of the container at the container terminal.

\subsection{Yard}

\footnotetext{
14 For a detailed Analysis and discussion of the functions and processes in the Yard Management cf. Lee and Chew (2013) and Hamedi (2010)

15 These "unproductive moves" are not remunerated to the container terminal operator and reduce its profits.

16 The transfer zone is also known as an interchange or transfer area. It represents the intersection from container terminal to logistics service providers in hinterland transport.
} 
The yard forms the interface between the water side and the landside connection with the transport of the container via railway terminals or by truck at the gate.

Figure 2 exemplifies two problem areas and outlines a solution.

Problem 3: 5\% of all container movements are unproductive stacking movements on the yard.

Problem 4: The yard is overloaded by large volumes of large container ships. Transit containers are waiting for the further transport by feeder ships.

Problem 3 relates to containers that must be stowed in the container blocks due to changes in planning on the yard, as the ship's congestion plan has changed. These unproductive moves tie up scarce equipment resources and are not paid for by the shipping company.

Problem 4 relates to the large container handling volumes from loading/deleting the ship, which again lead to the "peak load problem" because they temporarily overload the fixed infrastructure of the terminal. A part of the containers is dispatched to feeder sailed and must be stacked on the yard, unless direct loading from the seagoing vessel to the feeder vessel, which further increases the overload of the terminal with given resources and infrastructure.

A solution to Problem 1 can be achieved with NAVIS XVELA's previously presented cloud-based solution by accelerating and synchronizing planning for all stakeholders. A solution to Problem 2 can be achieved by capital extension of the terminal infra- and supra-structure as well as automation. However, technical, and economic restrictions must be observed, which go beyond the scope of this study.

A partial solution contribution can be achieved by optimizing the stacking of containers in automated block warehouses. Parts of the yard are served by automated cranes and controlled by a "BMS Block Management System". The result is a larger stacking height of the containers and a compaction of the container slots, as no manual stacking devices such as Van Carrier need to be used.

The BMS controls the optimal stacking of containers in block warehouses in coordination with the TOS and the Kai Crane (STS). Siemens has a similar project with Maersk Terminals in the port of Tangier in Morocco. ${ }^{17}$

\subsection{Land page}

Figure 2 will discuss two problem areas as an example and outline a solution.

Problem 5: Trucks jam at the gate.

Problem 6: Railway wagons are not available. The railway terminal $\mathrm{m}$ is congested in terms of capacity.

Problem 5 relates to congestion of trucks delivering containers at the gate. Traffic jams are caused by the technically limited capacity of the gate and time delays due to missing

\footnotetext{
${ }^{17}$ See the press release in Offshore Energy (2017) in more detail.
} 
documents and the control of accompanying documents. The result is a delayed loading time of the ship, as the resource planning of the equipment as well as the congestion planning at the terminal must be revised.

Problem 6 arises when railway wagons are not available in sufficient quantities for the transport of containers, for example because they are in the influx due to delayed train arrivals.

The solution to problem 5 is the use of IT systems that enable the truck to be cleared in predefined time windows, including the pre-registration of the accompanying documents. An example of this is the time window management of the container terminal operators HHLA and Eurogate in Hamburg (Truck Management). ${ }^{18}$

A solution to Problem 6 would be a platform that plans real-time exchanges between the shipping company, the container terminal operator and rail operators regarding the demand for parking capacity of containers on railway wagons, depending on the required time and makes the information available to stakeholders. Such a platform has not yet been presented. HacON's planning tools already enable partial solutions in the areas of timetable design and fault management. ${ }^{19}$

\section{Discussion and Conclusion}

An efficient global supply chain consisting of sea transport, land transport and air transport requires that the maritime supply chain also functions efficiently as an integral part. Barriers to efficiency in the maritime supply chain led to barriers to efficiency throughout the supply chain.

Container terminals are an essential part of the maritime supply chain, as they are the interface between the stakeholders shipping company, port, and hinterland transporters. Container terminals work efficiently when the planned target times for handling the container are synchronized with the planned target times for shipping the container until the goods are received from the container at the end customer. The container terminal operates efficiently regarding the target handling speed of the container only if the waterside handling is synchronized with the handling speed on the yard and the hinterland transport. Otherwise, traffic jams arise at different process transfer points on the terminal, which can only be solved by intermediate storage of the container and by reducing the overall process efficiency on the yard.

The present study has demonstrated the basic barriers to optimization with a focus on the water side, yard, and hinterland transport by means of solution examples. It has become apparent that the first cooperation of the stakeholders at the container terminal, in particular the shipping companies and the hinterland transporters, as well as the timecommunication speed of processes between the stakeholders, are of major importance for the overall efficiency of the handling speed of the containers. With the latter statement, the bridge can be built to the beginning of the question regarding the importance of

\footnotetext{
${ }^{18}$ Compare the HHLA press release: HHLA Information Pre-notification obligation for truck transports

${ }^{19}$ See the HACON planning tool in detail
} 
container terminals for the global supply chain: the entire supply chain is only as strong as the maritime supply chain can be designed.

\section{References}

Alessandro, Angelo, Sacone, Simona and Siri, Silvia

Modelling and optimal-receding-horizon control of maritime container terminals Journal of Mathematical Modelling and Algorithms 6(1) 2007 p. 109-133

\section{Beck, Bernhard}

Mikroökonomie, Publisher UTB, 2011

Bhardwaj, Manoi and Miller, Bryan (2018)

A New Frontier-Business Intelligence, Big Data \&The Impact on the Global Supply Chain Publisher:NAVIS

Burger, Alexander and Keipinger, Petra Investment

Investitionsrechnung, Verlag Vahlen compact, 2016

\section{Collins English Dictionary}

Publisher Harper Collins, Glasgow, 2000

\section{Gabler Business Dictionary}

Peak Load Pricing; Access: 01/03/2020

\section{HaCon Engineering Company mbH}

Link: https://www.hacon.de/; Access 04.01.2021

\section{HHLA Information Pre-notification obligation for truck transports}

Link: https://hhla.de/kunden/trucker-info/vormeldepflicht; Access 04.01.2021

\section{Hensher, David A. and Brewer, Ann M.}

Oxford University Press, New York, 2001

Joc. Com (2016) Cloud-based stowage system aims to boost port productivity https://www.xvela.com/news/hapag-lloyd-to-rollout-xvela-carrier-and-terminalcollaboration-services, Internet access 03.01.2021

\section{Lee, Loo Hay and Chew, Ek Peng (2013)}

A Review on Yard Management in Container Terminals Published in ResearchGate Access:

https://www.researchgate.net/publication/264171423_A_Review_on_Yard_Manageme nt_in_Container_Terminals

\section{Mangan, John, Lalwani, Chandra and Tim Butcher}

Global Logistics and Supply Chain Management Publisher John Wiley\&Sons, Reprinted May 2008

\section{NAVIS introduces $\mathbf{N} 4$ as a service}

Port Technology International, 01.12.2020; Access: 01.01.2020 
NAVIS XVELA https://www.navis.com/en/products/maritime-business-network/, Internet access 17.11.2019

Siemens to automate Africa's MedPort Tangier Terminal Offshore Energy, March1, 2017

\section{Tang, Chen (2006)}

Robust strategies for mitigating supply chain disruptions, International Journal of Logistics Research and Application, 9(1) p. 33-45

Cosco has designs ready for a 25,000-teu megaship

Maritime Gateway, 28.03.2019, access 03.01.2021 